\title{
TENSILE BEHAVIOR OF LASER BEAM WELDED (LBW) SIMILAR AND
} DISSIMILAR METALS

\author{
GAURAV. $\mathbf{S}^{\mathbf{1}^{*}}$, GANESAN. $\mathrm{C}^{2}$ \& ASOKAN. $\mathbf{R}^{3}$ \\ ${ }^{I}$ PG Scholar, School of Aeronautical Sciences, Hindustan Institute of Technology and Science, Chennai \\ ${ }^{2}$ Assistant Professor, School of Aeronautical Sciences, Hindustan Institute of Technology and Science, Chennai \\ ${ }^{3}$ Professor, School of Aeronautical Sciences, Hindustan Institute of Technology and Science, Chennai
}

\begin{abstract}
Welding of dissimilar metals has attracted the attention of researches worldwide because it has many advantages and challenges. Many welding techniques have been used by researchers for joining the dissimilar metal combination. Laser Beam Welding $(\mathrm{LBW})$ is one of the non-conventional and non-traditional methods to join both similar and dissimilar metals. In this study, the dissimilar metals such as Stainless Steel 304 and Stainless Steel $316 L$ are joined using Laser Beam Welding (LBW). The tensile tests of similar and dissimilar metals were conducted after joining using LBW as per the ASTM standards. An Analytical Study also was conducted to investigate the stress contours and deformations of welded specimens using ANSYS. Dissimilar metals after joined using LBW showed higher tensile strength when compared with similar metals. A good agreement was found between experimental and analytical results.
\end{abstract}

KEYWORDS: Laser Beam Welding $($ LBW $\&$ \& ASTM

Received: May 25, 2020; Accepted: Jun 15, 2020; Published: Jun 30, 2020; Paper Id.: IJMPERDJUN2020262

\section{INTRODUCTION}

The modern age demands lightweight, high strength structures with desired product properties which leads to the joining of dissimilar materials. Many industries rely on metals for the manufacturing of desired products and joining of dissimilar metals is an important application in industries. So, coming to metal joining processes welding is an efficient process for joining dissimilar metals and to achieve high strength and permanent joint. The joining of dissimilar metals with welding will only work if both the metals to be weld are mutually soluble with each other or else as an alternative a third metal that is soluble with both the metals are used to get a joint[1].

Stainless steel is one of the most popular materials for structural applications, due to its excellent physical and mechanical properties but it increases the structural cost. The stainless steel with different material properties metals is the most widely used in industries for manufacturing products [2]. The joining of stainless steel with other steel combinations has been widely attempted for applications in power industries, steam generators, nuclear applications, and in small products like hydraulic valves. Welding stainless steels to carbon and low alloy steels are established methods in the process and construction industries. Dissimilar metal welds involving stainless steel can be done using most full fusion weld methods, including LBW (Laser Beam Welding) and MIG (Metal Inert Gas) welding process. Weld procedures using filler (consumable) enable better control of joint corrosion resistance and mechanical properties. The dissimilar steels consist of distinct chemical composition and the major problem arises when welding dissimilar steels are the formation of an intermetallic compound in the welded region. In welding of dissimilar steels welding process and welding parameters plays an important role in the formation of a good welded 
joint. The TIG welding process is an arc welding process uses a non-consumable tungsten electrode to produce the weld. The weld area is protected from the atmosphere with a shielding gas generally Argon or Helium or sometimes a mixture of Argon and Helium.[1] Filler metal may also feed manually for proper welding. In MIG welding process a continuous and consumable wire electrode is used. A shielding gas generally argon or sometimes a mixture of argon and carbon dioxide are blown through a welding gun to the weld zone.

Ajit Hooda et al,[3] studied for the material AISI 1040 Medium carbon Steel and take input parameter as welding voltage, current, wire speed and gas flow rate and the response was RSM (Response Surface Methodology) for maximum yield strength of joint. The similar weld joint of AISI 1040 material was developed effectively with MIG welding with selected range of input variable parameters. The longitudinal yield strength is greater than the transverse yield strength.

\section{MATERIAL AND METHODS}

Stainless steel finds its use in the Aeronautical and Aerospace industry used in outdoor sealing tanks, fasteners, engine turbine engine internal parts, nozzle parts, turbine blades, top of the bat lab. Stainless steel 304 and stainless steel 316L being the two main metals used in the region of Aircraft and Space for hand-held under high temperatures, due to the properties they display such as corrosion resistance, heat resistance, weld strength, heat resistance and heat treatment, machinability and positive energy. [2]

Table 1: Material Composition of SS304[2]

\begin{tabular}{|l|l|l|l|l|l|l|l|l|l|}
\hline Element & $\mathrm{C}$ & $\mathrm{Mn}$ & $\mathrm{P}$ & $\mathrm{S}$ & $\mathrm{Si}$ & $\mathrm{Cr}$ & $\mathrm{Ni}$ & $\mathrm{Fe}$ & $\mathrm{N}$ \\
\hline SS304\% & 0.08 & 2 & 0.045 & 0.03 & 0.75 & 20 & 10.5 & 66.5 & 0.10 \\
\hline
\end{tabular}

The 304 stainless steel used in standard applications can be named as shown in Table 1. Chromium and nickel are the major components. Chromium present rather than iron provides corrosion-resistant material. 316L stainless steel has the structural features shown in table 2 below. These are called Mo alloys that provide additional metal material for corrosion resistance and the reduction of fracture surface area.

Table 2: Material Composition of SS316L[2]

\begin{tabular}{|l|l|l|l|l|l|l|l|l|l|l|}
\hline Element & $\mathrm{C}$ & $\mathrm{Mn}$ & $\mathrm{P}$ & $\mathrm{S}$ & $\mathrm{Si}$ & $\mathrm{Cr}$ & $\mathrm{Ni}$ & $\mathrm{Mo}$ & $\mathrm{N}$ & $\mathrm{Fe}$ \\
\hline SS316L\% & 0.03 & 2 & 0.045 & 0.03 & 0.75 & $16-18$ & $10-14$ & $2-3$ & 0.10 & $60-70$ \\
\hline
\end{tabular}

\section{Laser Beam Welding}

Welding is a permanent process of joining two objects. There are several welding processes such as arc welding, gas welding, solid-state welding, resistance welding, thermochemical corrosion, and radiant energy welding. Laser beam welding and Friction stir welding are the two main joining methods used in the Aeronautical and Aerospace industries. The main advantage of using these methods is that they can be used with different metals, complex components can be integrated, less time consuming, faster combustion rate, lower thermal distortion, etc. Laser beam welding is the joining technique used to find welds with greater depth of Equation width, higher aperture, higher accuracy, and smaller deviation.[2] 
These provide good strength for the joint metals. Aircraft components such as engine nozzles, turbine blades, etc. are set at very high temperatures. The aircraft parts are subjected to a maximum temperature of about $1400^{\circ} \mathrm{C}$ in the exhaust compartment where the high-pressure gas exits the pump duct. This makes it necessary to obtain the strength and mechanical properties of the joints mixed under extremely high temperatures. The Strength of Laser beam welded samples are studied by conducting experimental as well as analytical study to determine the tensile property of the welded joint.[2]

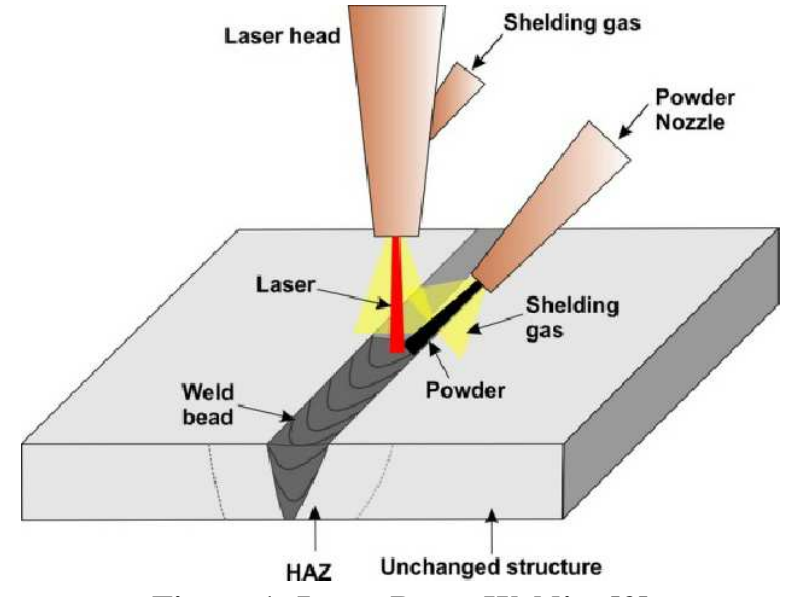

Figure 1: Laser Beam Welding[2]

The laser beam welded sample is shown in Figure 1. Argon (Ar) was used as a shielding gas with a constant flow rate of 10 LPM. Argon gas avoids the fusion zone contamination by making the gas remain neutral and thereby not involving in a chemical reaction. The laser beam welding is done as per the given table 3 .

Table 3: Weld Parameters[2]

\begin{tabular}{|l|l|}
\hline \multicolumn{2}{|c|}{ Macro welding parameters } \\
\hline Laser power & $1800 \mathrm{watt}$ \\
\hline Pulse width & $20 \mathrm{~ms}$ \\
\hline Bead diameter & $18 \mathrm{~mm}$ \\
\hline Frequency & $20,000 \mathrm{~Hz}$ \\
\hline Speed & $2 \mathrm{~m} / \mathrm{min}$ \\
\hline Gas flow & $10 \mathrm{LPM}$ \\
\hline
\end{tabular}

\section{Tensile test}

The tensile specimen is done according to the ASTM E646-98 standard with a gauge length of $50 \mathrm{~mm}$ utilizing a lathe machine and the tensile test is carried out by Universal Testing Machine (UTM).[2]

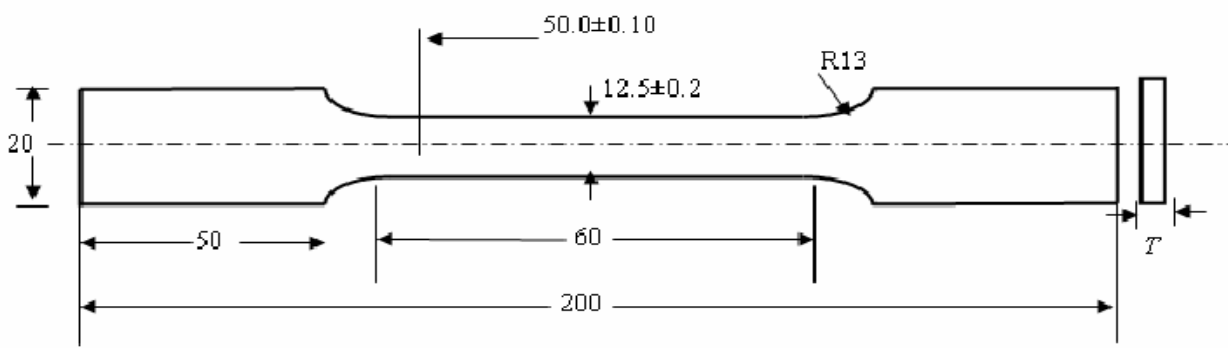

Figure 2: ASTM Samples[2] 


\section{Finite Element Analysis}

It was evident from the tensile test that the welded samples turned out to have good strength in the weld region. To check for the exactness of the ultimate tensile strength of the welded samples, the model of the sample was prepared in the ANSYS workbench as per the dimension given below and the model is shown in Figure. The mechanical properties of the material were specified. Table 5 Dimensions and mechanical properties of laser beam welded samples. The model is then meshed according to the parameters given below and the model is given in Figure 4.

Table 4: Mesh Parameters

\begin{tabular}{|l|l|}
\hline Length & $200 \mathrm{~mm}$ \\
\hline Breadth & $20 \mathrm{~mm}$ \\
\hline Thickness & $3 \mathrm{~mm}$ \\
\hline Material & SS304 and SS316L \\
\hline Density & $7.85 \mathrm{e}-005 \mathrm{~kg} / \mathrm{mm} 3$ \\
\hline Yield Strength & $250 \mathrm{Mpa}$ \\
\hline Tangent Modulus & $1450 \mathrm{Mpa}$ \\
\hline Young's Modulus & $0.2 \mathrm{e}-005 \mathrm{Mpa}$ \\
\hline Poisons ratio & 0.3 \\
\hline \multicolumn{2}{|c|}{ Sizing } \\
\hline Use advanced Size Function & On: Curvature \\
\hline Relevance Centre & Fine \\
\hline Initial Size Seed & Active Assembly \\
\hline Smoothing & High \\
\hline Transition & Slow \\
\hline Growth Rate & 1.2 \\
\hline Minimum Edge Length & 3 \\
\hline Use Automatic Length & None \\
\hline Inflation Option & Smooth Transition \\
\hline Transition Ratio & 0.272 \\
\hline Maximum Layer & 5 \\
\hline Growth Rate & 1.2 \\
\hline Nodes & 15982 \\
\hline Elements & 2680 \\
\hline Mesh Metric & None \\
\hline
\end{tabular}

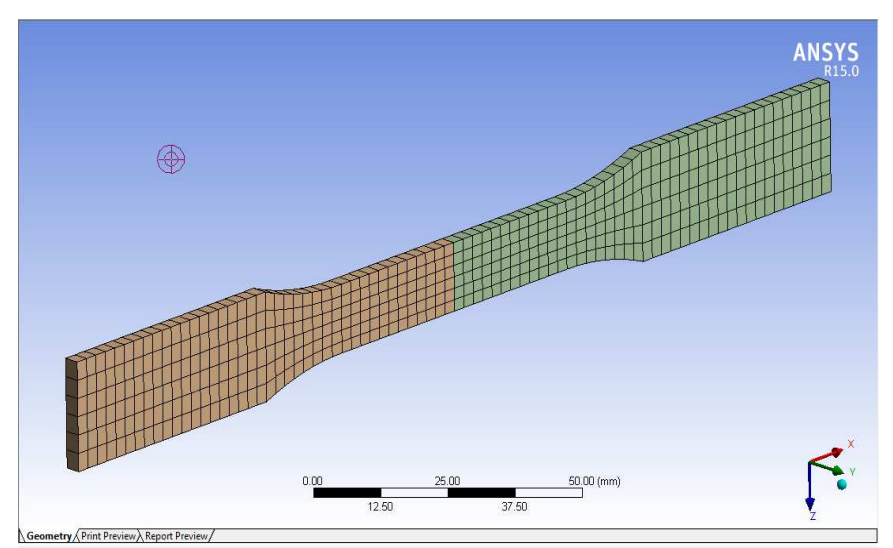

Figure 3: Meshed Model

The model of a welded sample of stainless steel 304 and stainless steel 316L is meshed as per the mesh parameters given in the table. The model is meshed with nodes being 15982 and elements being 2680. 


\section{RESULTS AND DISCUSSIONS}

\section{Tensile Test Results of Similar Metals(SS304- SS304)}

The welded samples were tested for maximum tensile strength under a tensile load of $20 \mathrm{KN}$ in the Universal testing machine (UTM). The ASTM Standard welded specimens are shown in the below Figure 2.

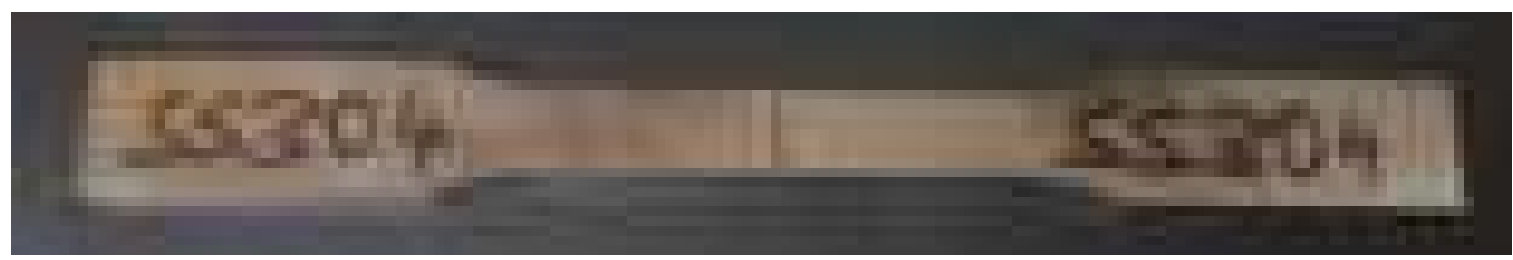

Figure 4: Laser Beam Welded Samples

Table 5 Tension Test of Sample 304 and 304

\begin{tabular}{|l|c|c|c|c|}
\hline Weld trial & Power $(\mathbf{W})$ & Peak load $(\mathbf{K N})$ & Travel at peak $(\mathbf{m m})$ & $\begin{array}{c}\text { Tensile strength } \\
(\mathbf{N} / \mathbf{m m})\end{array}$ \\
\hline Normal & 1800 & 20.40 & 0.49 & 560.56 \\
\hline
\end{tabular}

The Figure 4 sample is subjected to loads from $1 \mathrm{KN}$ and increased until the material breaks exactly at the weld portion. Thus the sample takes a maximum load of $20.40 \mathrm{KN}$ and broke. The maximum tensile strength noted was 560.56 MPa. The graph 15 shows the tensile behaviour of load $(\mathrm{kN})$ vs deformation(mm).

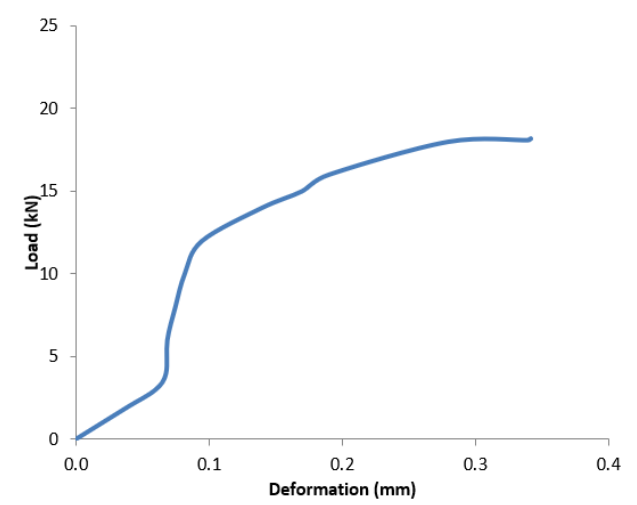

Figure 5: Tensile Test Graph for SS304 \& SS304

The Analytical Study of SS304 \& SS304 model breaks taking a load of 20.40 KN, with a maximum deformation of $0.49 \mathrm{~mm}$, as shown in Figure 5.

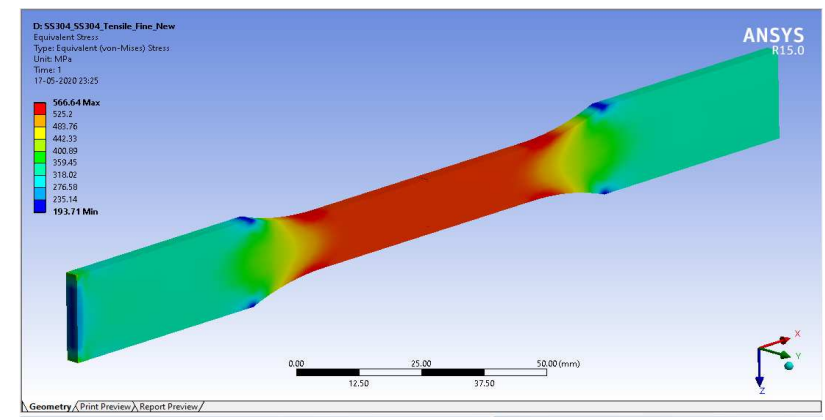

Figure 5: Stress Contour of SS304-SS304 
The Stress value obtained varied from a minimum of $193.71 \mathrm{Mpa}$ to a maximum of 566.64Mpa.The tensile behavior of material is shown in Figure 6.

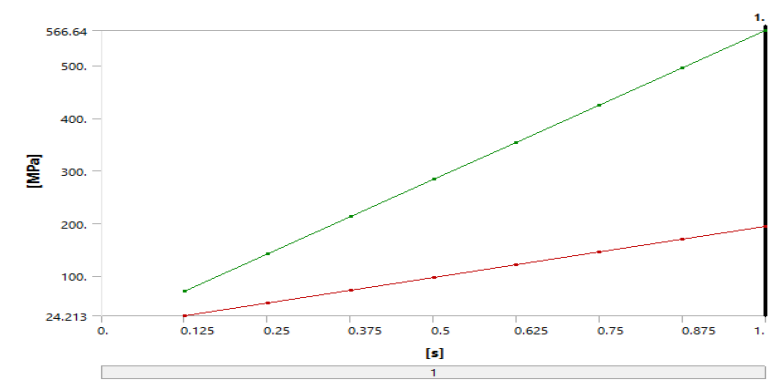

Figure 6: Graph of Tensile stress (Mpa) vs Time(s)

\section{Tensile Test Results of Similar Metals(SS316L - SS316L)}

The welded samples were tested for maximum tensile strength under a tensile load of $19.1 \mathrm{KN}$ in the Universal testing machine (UTM). The ASTM Standard welded specimens are shown in the below Figure 7.

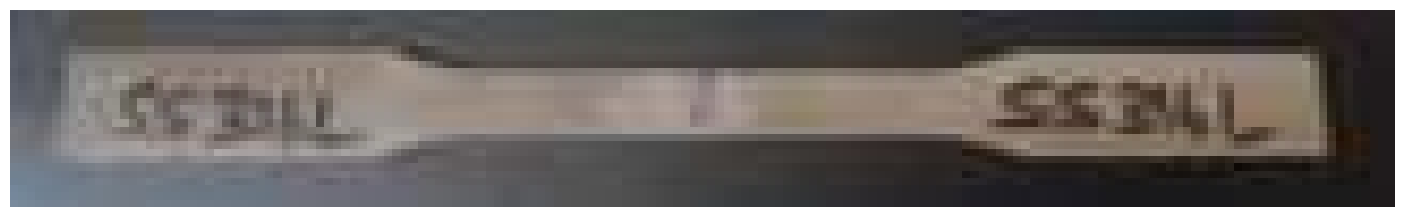

Figure 7: Laser Beam Welded SS316L

Table6: Tension Test of SS316L-SS316L

\begin{tabular}{|l|c|c|c|c|}
\hline Weld Trial & $\begin{array}{c}\text { Power } \\
(\mathbf{W})\end{array}$ & Peak Load $(\mathrm{KN})$ & Travel at Peak $(\mathbf{m m})$ & $\begin{array}{c}\text { Tensile Strength } \\
\text { (N/mm2) }\end{array}$ \\
\hline Normal & 1800 & 19.1 & 0.391 & 452.3 \\
\hline
\end{tabular}

The Figure 7 sample is subjected to loads from $1 \mathrm{KN}$ and increased until the material breaks exactly at the weld portion. Thus the sample takes a maximum load of $19.1 \mathrm{KN}$ and broke. The maximum tensile strength noted was 452.3 $\mathrm{MPa}$. The Figure 9 shows the tensile behaviour of $\operatorname{load}(\mathrm{kN})$ vs deformation $(\mathrm{mm})$.

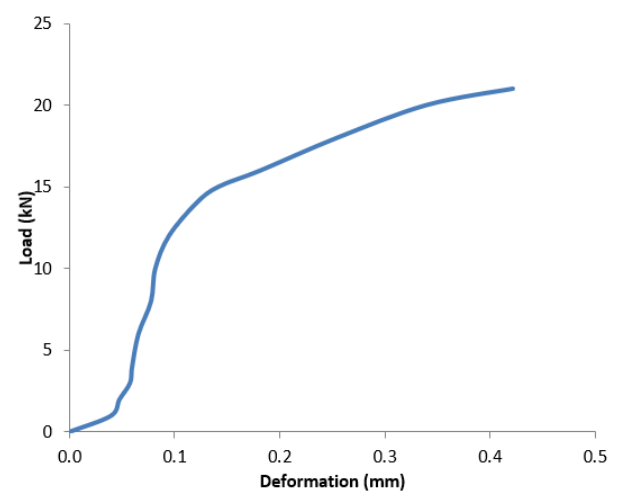

Figure 8: Tensile test Graph for SS316L \& SS316L

The Analytical Study of SS316L \& SS316L model breaks taking a load of $20.40 \mathrm{KN}$, with a maximum deformation of $0.49 \mathrm{~mm}$, as shown in Figure 9. 


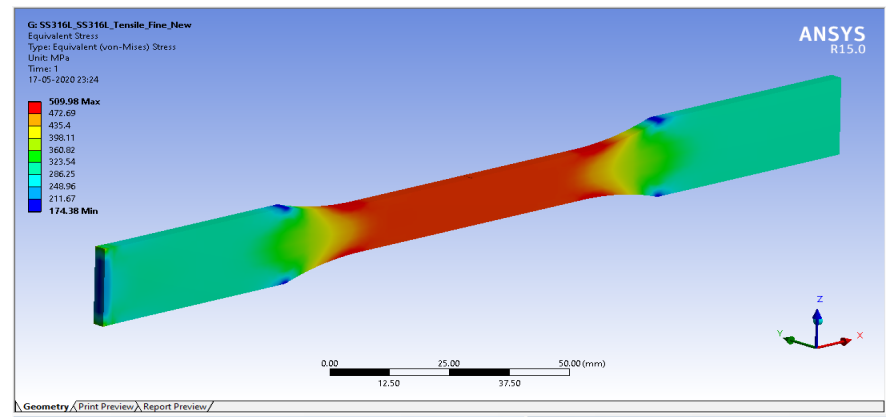

Figure 9: Stress Value obtained from FEA

The Stress value obtained varied from a minimum of $174.38 \mathrm{Mpa}$ to a maximum of 509. 98Mpa.The tensile behavior is shown in Figure 10.

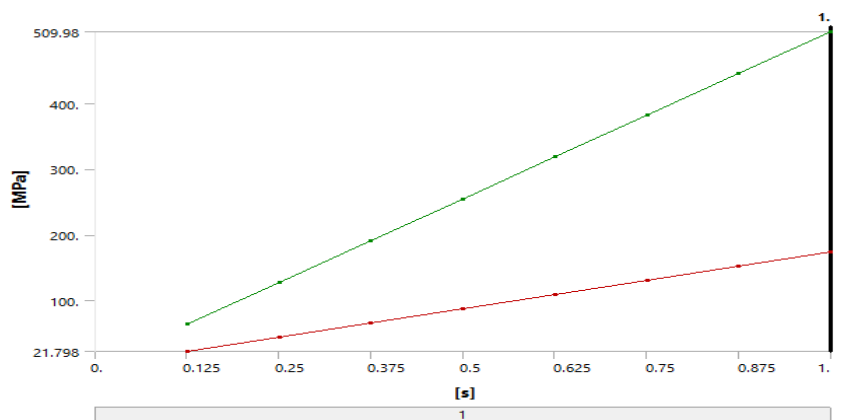

Figure 10 Graph of Tensile stress (Mpa) vs Time(s)

Tensile test results of similar metals(SS304- SS316L)

The welded samples were tested for maximum tensile strength under a tensile load of $20.80 \mathrm{KN}$ in the Universal testing machine (UTM). The ASTM Standard welded specimens are shown in the below Figure 11.

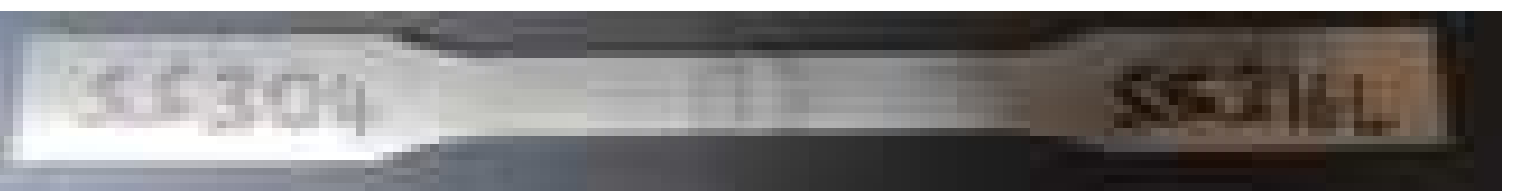

Figure 11: Laser Beam welded SS304 \& SS316L

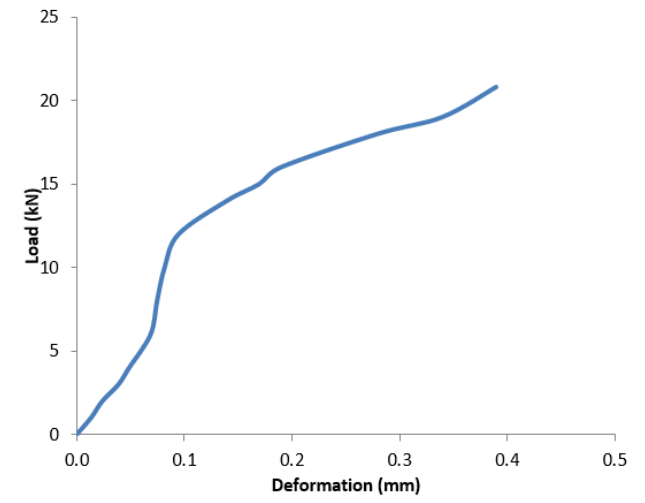

Figure 12: Tensile Test Graph for SS304 \& SS316L

Table 7: Tension Test of 304 and 316L samples 


\begin{tabular}{|c|c|c|c|c|}
\hline Weld Trial & $\begin{array}{c}\text { Power } \\
(\mathbf{W})\end{array}$ & Peak Load $(\mathrm{KN})$ & Travel at Peak (mm) & $\begin{array}{c}\text { Tensile Strength } \\
(\mathbf{N} / \mathbf{m m} \mathbf{2})\end{array}$ \\
\hline Normal & 1800 & 20.80 & 0.4439 & 580.62 \\
\hline
\end{tabular}

The Figure 13 sample is subjected to loads from $1 \mathrm{KN}$ and increased until the material breaks exactly at the weld portion. Thus, the sample takes a maximum load of $20.80 \mathrm{KN}$ and broke. The maximum tensile strength noted was 580.62 $\mathrm{MPa}$. The Figure 9 shows the tensile behaviour of load $(\mathrm{kN})$ vs deformation $(\mathrm{mm})$.

The Analytical Study of SS304 \& SS316L model breaks taking a load of $20.40 \mathrm{KN}$, with a maximum deformation of $0.49 \mathrm{~mm}$, as shown in Figure 13.

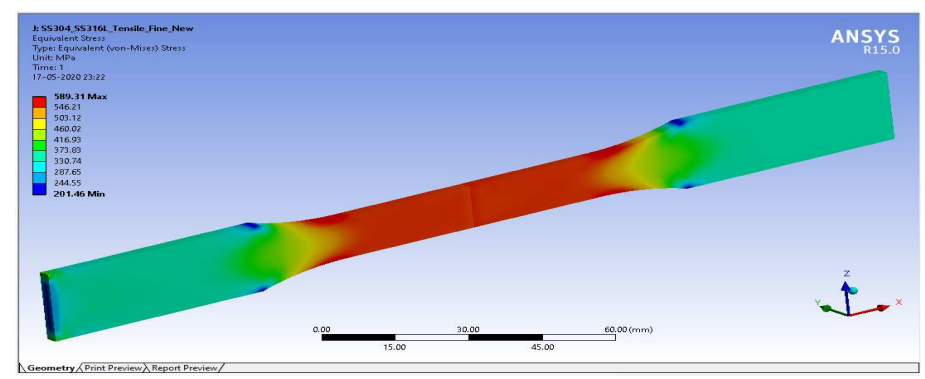

Figure 13 Stress Value obtained from FEA

The Stress value obtained varied from a minimum of $201.46 \mathrm{Mpa}$ to a maximum of $580.62 \mathrm{Mpa}$.The tensile behavior is shown in Figure 13.

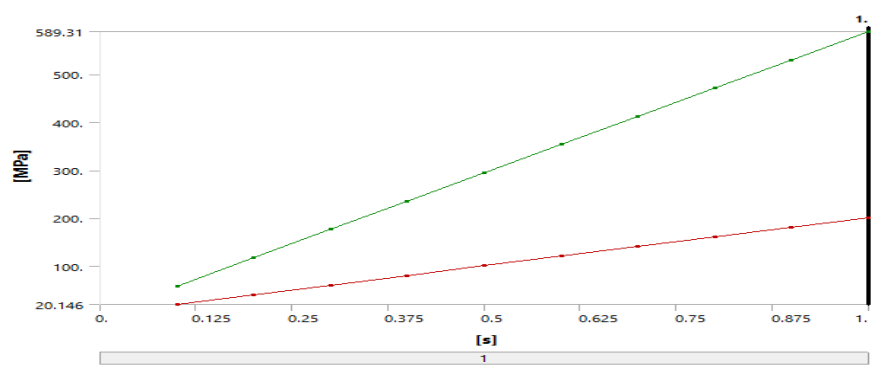

Figure 14: Graph of Tensile Stress (Mpa) vs Time(s)

\section{COMPARATIVE STUDY}

Table 8 Experimental Tensile properties of SS304 \& SS316L

\begin{tabular}{|c|c|c|c|}
\hline Samples & $\begin{array}{c}\text { Peak load } \\
(\mathbf{k N})\end{array}$ & $\begin{array}{c}\text { Experimental } \\
\text { Tensile Strength(N/mm2) }\end{array}$ & $\begin{array}{c}\text { FEA } \\
\text { Tensile Strength } \\
(\mathbf{N} / \mathbf{m m} \text { ) }\end{array}$ \\
\hline 304 \& 316L & 20.80 & 580.62 & 589.31 \\
\hline 304 \& 304 & 20.40 & 560.56 & 566.64 \\
\hline 316L \& 316L & 19.1 & 452.3 & 509.98 \\
\hline
\end{tabular}

Tabulated results of Experimental and FEA show that dissimilar welded samples show higher tensile properties compared to similar welded samples are is shown in the above table 8.

\section{CONCLUSIONS}

In this paper, we have analyzed the strength of similar and dissimilar laser beam welded joint of stainless-steel materials 
$316 \mathrm{~L}$ and 304 by keeping the speed of the weld constant and the laser powers. The dissimilar stainless-steel materials are welded samples that show good tensile properties compared to the similar metals welded samples by using this welding technique. The metal samples are welded with $1800 \mathrm{w}$ laser power along with a bead width of $3 \mathrm{~mm}$ on one side of the sheet. From the analysis, we have found that dissimilar weld joints gave the best results compared to similar welded samples in tensile test aspects. Tests were done in two phases one is the experimental analysis of the strength of the weld by subjecting it to various loads and checking for its tensile strength. Second by obtaining the theoretical results, using the FEA method and comparing these results with that of the experimental values. Thus, making our result acceptable. From the discussion made in the result section, it is clear that in experimental results dissimilar welded samples turned out to be the best samples with a good tensile strength of 580.62MPa,

However, the welded samples results from the experimental study were almost near to the theoretical tensile strength of 589.31 MPa. This proved that the tensile strength found out experimentally was correct and was the best value.

\section{REFERENCES}

1. M.Gaffar. M. Shankar, P.Sampath Kumar, and V.V Satayanarayana, Experimental Investigation on Welded Joints of Dissimilar Steels, "Int. J. Curr. Eng. Technol., vol.77, no. 33, pp. 2277-4106,2017

2. K. Lingadurai,R.Mukesh, H.S.Siddesha, and R. Sivasubramaniyam, "On Use of Laser Beam Welding for Austentic Stainless Steel Type 316L and Stainless Steel Type 304 for Aerospace Applications., "Int. J. Innov.Technol. Explor. Eng., vol 9, no 3, pp. 1546-1554, 2020.

3. Ajit Hoodal, Ashwani Dhingra and Satpal Sharma, "Optimization Of MIG welding process parameters to predict maximum strength in AISI 1040" International journal of Mechanical Engineering and Robotics Research Vol. 1, No. 3,3 , October 2012. ISSN $2278-0149$

4. B. Ramesh Kumarl \& R. Gangradeyl, "Characterization of laser beam welded SS304 for fusion reactor applications" International journal of manufacturing technology and industrial engineering (IJMTIE) Vol. 1, No. 1, January-June 2011, pp. 25-29.

5. Ms. Deepika Harwani*, Mr. Kapil Banker** "Welding Of Dissimilar Metal Alloys by Laser Beam Welding \& Friction Stir Welding Techniques" Journal of Engineering Research and Applications www.ijera.com ISSN : 2248-9622, Vol. 4, Issue 12( Part 1), December 2014, pp.64-70

6. Scotti, A. Mapping transfer modes for stainless steel gas metal arc welding. Sci. Technol. Weld. Join. 2000, 5, 227-234.

7. I.N. Nawi a, *, Saktiotob, M. Fadhalic, M.S. Hussaind, J. Alie and P.P. Yupapinf, "Nd:YAG Laser Welding of Stainless Steel 304 for Photonics Device Packaging" 20 December 2010

8. A. Klimpel, A. Lisiecki, T. Figiel: High power diode laser welding of austenitic steel, Polish Welding Review 4 (2002),1-5

9. Mahmoud M. Tash, "Laser welding of similar stainless steels (304/304) and dissimilar stainless steel (304)/carbon steel (A36) alloys", International Journal of Advanced Technology in Engineering and Science Volume No.03, Issue No. 03, March 2015

10. Y. Tzeng: Gap-free lap welding of zinc-coated steel using pulsed $\mathrm{CO} 2$ laser, International Journal of Advanced Manufacturing and Technology 29 (2006) 287-295

11. Rakesh Bhadral, Pankaj Biswas2 and M. Ravi Sankar3, "Effect of process parameters on thermal history of laser welding of AISI-304 stainless steel", December 12th 2014 
12. Mr. Abhay D. Nichite P.G student, Department of Mechanical Engineering, Pillai Institute of Information Technology, New panvel, India.

13. Klimpel, A. \& Lisiecki, A. (2007). Laser Welding of Butt Joints of Austenitic Stainless Steel AISI 321. Journal of Achievements in Materials and Manufacturing Engineering, 25, 1.

14. Kumar, A. P., \& Krishna, C. S. R. Sensitivity Analysis Of Tig Welding Parameters For Astm-500 Grade B Weldments.

15. Darwins, A. K., \& Satheesh, M. (2017). Effect Of Friction Stir Welding Processon Mechanical Propertiesand Microstructure Of Ze42 Magnesium Alloy.

16. Seif, M. A., \& Nasr, M. M. A Comparative Study Of Assembling Methods Of Nonwoven Bags Traditional Sewing Vs Welding Seaming.

17. Rathod, C. H. A. N. D. A. R., \& Reddy, G. K. (2016). Experimental investigation of angular distortion and transverse shrinkage in CO2 arc welding process. International Journal of Mechanical Engineering, 5 (4), $21,28$. 